In: Historiographia Linguistica 37 (2010), 165-191.

\title{
Two Notions of 'research program' and the Historiography of Generative Linguistics*
}

\author{
András Kertész \\ University of Debrecen
}

\section{Introduction}

As is well-known, since the mid-sixties of the last century, and beginning just a few years after the publication of Thomas Kuhn's seminal The Structure of Scientific Revolutions in 1962, generative grammar has been associated with the notions of 'Chomsky's revolution' and 'the generative paradigm'. However, the application of Kuhn's approach to generative linguistics gave rise to serious counter-arguments as well and has resulted in heated controversies from the seventies till the present day.

One of the problems which the debates have led to is the extreme diversity of historiographic frameworks for generative linguistics. For example, with respect to Chomsky (1957), competing claims have been made that the appearance of Syntactic Structures (a) triggered a scientific revolution in the Kuhnian sense (Thorne 1965, Searle 1972, and many others); (b) triggered a scientific revolution in the sense of Laudan (1977; cf. Newmeyer 1986); (c) contributed to the victory of Zellig S. Harris' approach over that of Trager and Smith within Post-Bloomfieldian structuralism (Hymes \& Fought 1981); (d) is "[...] basically Post-Saussurean structuralism" (Koerner 2002: 163) and appears to be the evolution of the previous state of (PostBloomfieldian) linguistics rather than a revolution as such (Koerner 2002: 185); (e) is a contribution to linguistic metatheory rather than linguistics (Seuren 1998); (f) was followed by a palace coup and revolutionary rhetoric without being intellectually revolutionary (Murray 1994); (g) was followed by the use of rhetorical tools among others based on fallacious argumentation by Chomsky and his adherents (Harris 1993).

\footnotetext{
* On the occasion of: Cedric Boeckx, Linguistic Minimalism: Origins, concepts, methods, and aims (Oxford \& New York: Oxford University Press, paperback edition, 2006), x+246 pp. ISBN10: 0199297584, ISBN13: 9780199297580, \$44.99; Pius ten Hacken, Chomskyan Linguistics and its Competitors (London \& Oakville: Equinox, hardback edition, 2007), 366 pp. ISBN-10 1845530543 , ISBN-13, 9781845530549, £55.00/\$85.00.

I am very grateful to Dr Bruce E. Nevin and two other anonymous referees for their insightful comments on previous drafts of this text. Any remaining shortcomings are entirely my own responsibility.

Work on this article was supported by the Research Group for Theoretical Linguistics of the Hungarian Academy of Sciences and Grant No. K 77823 of the Hungarian Scientific Research Fund.
} 
With respect to Chomsky (1965), several assumptions have been considered as well, for example: (a) it triggered a scientific revolution in a Kuhnian sense (McCawley 1976, Koerner 1989: 190-191); (b) the impact of Aspects did not conform to the Kuhnian concept of 'revolution' but is rather the result of, first, the personalities involved and second, the inadequate application of the methodological norms of the natural sciences (Lakoff 1989); (c) the impact of Aspects and the demise of generative semantics was rooted in ideological factors (Huck \& Goldsmith 1995).

Murray (1994: 238-239) has even proposed that Chomsky \& Halle (1968), rather than Syntactic Structures, was the 'revolutionary document'.

Chomsky himself did not reject the idea that the Principles \& Parameters approach was revolutionary (to mention just two examples, in Chomsky 2002: 95 and Grewendorf 1995: 219-222). In strict opposition to this, Jäger (1993) evaluated the development which culminated in the Principles \& Parameters approach as the decline of linguistics and the erosion of its subject matter.

There are also diverse historiographic characterizations of Minimalism (Chomsky 1995). Piatelli-Palmarini (1998: xxii) for example speaks of "[...] a revolution within a revolution”, whereas Seuren (2004: 4), in contrast, calls the Minimalist Program "[...] a sad example of spurious science". In the view of Lappin et al. (2000a, b, 2001) the wide acceptance of the Minimalist Program is rooted in Chomsky's authority rather than the implementation of the Principles \& Parameters approach.

Moreover, John E. Joseph describes the whole history of generative linguistics as including "not one, but easily a dozen large-scale or small-scale linguistic revolutions", many of which "have been led by the same man, revolting against his own program of a few years before: Noam Chomsky, Serial Revolutionary" (Joseph 1995: 380; emphasis added: AK).

However concise this overview of the state of the art in the historiography of generative linguistics is, it clearly shows that there is anything but agreement on the historiographic framework to be applied and the results that such applications may yield.

The second crucial problem for historiographic analyses is of course, how to capture the genetic relationships involved, not only between Post-Bloomfieldian structuralism and early generative linguistics, but also between different stages of generative linguistics — such as, for example the Standard Theory, Government \& Binding Theory, and the Minimalist Program.

Thirdly, it is no less difficult to account for a series of synchronic relationships which were the result of the developments of the past 50 years. There is a problem in characterizing adequately the outcome of the developments leading to alternative approaches - e.g., Lexical-Functional Grammar (LFG) or Head-driven Phrase Structure Grammar (HPSG) etc. - which, while seriously questioning basic tenets of Chomsky's claims, have also been considered as elements of the generative movement and bear intradisciplinary relationships to Chomsky's works. What is more, the interdisciplinary relationships, at successive stages, between generative linguistics and the natural sciences such as physics and biology is open to discussion. Finally, there are at present different versions of 'minimalism', and the relationships among these need to be explored as well.

The two works under review tackle these issues and seem to have a lot in common. Both are textbooks; both include substantial chapters on the history of generative linguistics, although historiography is not their only concern; and instead of Kuhn's 'paradigm', both apply the notion of 'research program', albeit in two quite different senses. 
Against the background that I have sketched, we will now evaluate each book in turn with respect to the following three questions:

1) To what extent is the historiographic framework the author has chosen tenable?

2) How does the framework chosen capture the diachronic relationship between each stage of generative linguistics and its predecessors?

3) How does the framework chosen capture the synchronic relationships between Chomsky's generative linguistics and competing approaches within theoretical linguistics; between Chomsky's generative linguistics and other disciplines such as physics and biology; and between different versions of minimalism?

We will use these questions to evaluate the structure and content of ten Hacken's book in Section 2, and Boeckx's book in Section 3. In Section 4 we will draw some general conclusions paving the way for further research.

\section{Chomskyan linguistics as a research program}

\subsection{The notion of 'research program'}

Pius ten Hacken's textbook is unique in at least two respects. First, unlike most textbooks, it does not introduce the reader to one particular version of generative linguistics, but it sets out to give a comprehensive overview of different theories both diachronically and synchronically. As regards diachrony, it sketches the process that led from Post-Bloomfieldianism through the Standard Theory and Government \& Binding Theory to the Minimalist Program. Synchronically, it analyzes the relationship between what the author calls 'Chomskyan linguistics' and its (intradisciplinary) competitors: Lexical-Functional Grammar (LFG), Head-driven Phrase Structure Grammar (HPSG), Generalized Phrase Structure Grammar (GPSG) and Ray Jackendoff's linguistics (see Jackendoff 2002). Second, the diachronic and synchronic comparisons are based on central ideas of the philosophy of science and have, accordingly, a strong methodological bias. We will explain these two issues in the reverse order.

Chapter 1 of the book is a concise introduction to the philosophy of science. ${ }^{1}$ It starts with the 'empirical cycle', which represents scientific inquiry as a cyclical procedure. In this procedure, observations lead to empirical laws which, in turn, are the basis of a theory; from the theory further laws are then predicted which feed back to guide the observations. However, as the author shows, the empirical cycle raises a series of problems which different approaches to the history and philosophy of science have tried to solve. Among these, the most promising one is Kuhn (1970). Ten Hacken emphasizes that Kuhn's paradigms have both social and intellectual aspects. For the purposes of the book the author suggests we replace the notion 'paradigm' with that of 'research program' which focuses on the intellectual aspects and disregards the social ones: "A research programme is the set of assumptions, tacit or explicit, which make research along the lines of the empirical cycle possible" (p.

\footnotetext{
${ }^{1}$ In the overview ten Hacken sticks to the analytical philosophy of science and rejects novel approaches such as the sociology of scientific knowledge. In general, his presentation of some tenets of the former is correct. However, on p. 24 he falsely describes Steve Woolgar as a representative of the Strong Program for the sociology of scientific knowledge, which he is not. The Strong Program is associated with the Edinburgh School whose leading personality is David Bloor (see Bloor 1976). There are several trends in the sociology of scientific knowledge, and Woolgar's (1988) views differ significantly in certain respects from those of Bloor’s Strong Program.
} 
18). The author emphasizes that this notion is different from Lakatos's (1970) concept of 'scientific research program'. He does not intend to develop a general approach to the philosophy of science and restricts the scope of the notion of 'research program' to generative linguistics.

There are consequences here for the methodological foundation on which the analyses in the book are built, because research programs in this sense include several empirical cycles. Since theories are - as mentioned above - elements of empirical cycles, this means that a research program may include more than one theory. Within a research program, theories can be compared because they share the standards that are valid for the whole research program. They are diachronically ordered or, from a synchronic point of view, tackle different issues. Therefore, this notion of 'research program' seems to provide a tool for capturing the unity and the diversity of generative linguistics both diachronically and synchronically.

The author introduces the notion of 'progress in a research program' as well: a theory T2 represents progress with respect to a theory T1 if the former covers more data and offers a deeper explanation of the data than the latter (p. 23).

Another crucial suggestion is a new definition of the notion of 'scientific revolution'. Since its definiens includes the concept of 'research program' in the above sense, it focuses on the intellectual aspects of scientific inquiry by eliminating the social ones from Kuhn's original idea: “A revolution is a change of research program” (p. 25).

Now, let us come back in a somewhat more detailed way to the first main feature of the book mentioned at the beginning of this section, and see how the central notion of 'research program' and the methodological background thus developed facilitate both a diachronic and a synchronic analysis of generative linguistics.

\subsection{The diachronic aspects of Chomskyan linguistics}

As regards the diachronic aspect discussed in Chapters 2 and 3 of the book, the result of the author's analysis which the application of his methodological framework yields can be summarized in the form of two theses. The first is the author's solution to the problem as to what extent it is justified to assume the unity of Chomskyan linguistics from a diachronic point of view. In particular, in the literature its unity has been questioned because radical differences have been assumed between the Standard Theory, Government-Binding Theory, and the Minimalist Program. The author solves the problem by arguing that although these are different theories and there were important changes in the theoretical framework, they belong to the same research program and are not divided by revolutionary breaks (p. 123). On the one hand, “[...] there can be no doubt [...] that the research programme of Chomskyan linguistics was fully in place in 1960 at the latest" (p. 104) and that "[...] its development takes the form of a gradual specification rather than a substitution of older assumptions by new ones” (p. 40). For instance, ten Hacken quotes passages from Chomsky's early writings which show that the native speaker's competence has been one of Chomsky's key issues from the late 1950s on. On the other hand, he does not see a dividing line between Government \& Binding Theory and the Minimalist Program: "The entire model adopted in GB-theory [...] is still valid in the MP” (p. 121). ${ }^{2}$ The Minimalist Program addresses two additional topics which indicate that it differs from Government \& Binding Theory, but which do not turn it into a new research program: the evolution of the language faculty and its realization in the brain. Thus, the unity of

\footnotetext{
${ }^{2}$ The full model of Chomsky's research program is summarized in Figure 2.7. on p. 86.
} 
Chomskyan linguistics is explained by the claim that from the very beginning on it has been a coherent research program, whereas its diversity is attributed to the fact that this research program consists of a chronologically ordered series of theories. It is worth remarking that in this sense the Minimalist Program is treated as a theory, too. ${ }^{3}$ So, the emphasis is on the coherence of the research program and the inconsistencies between Chomsky's views are not touched on.

The author's second main claim concerning the diachronic aspect of generative grammar is his answer to the question of whether the transition from PostBloomfieldian structuralism to generative transformational grammar corresponds to a scientific revolution. In chapter 3 the basic issues of Post-Bloomfieldian linguistics are discussed and then both the latter's continuities with and differences from early generative linguistics are analyzed. The author argues that Post-Bloomfieldian and Chomskyan linguistics are incommensurable, and therefore they constitute two different research programs. Applying the new concept of 'revolution' (which is defined as a change of research program), he reaches the following conclusion ( $\mathrm{p}$. 179; emphasis added: AK):

\begin{abstract}
The emergence of Chomskyan linguistics was a revolution because it is based on a different research programme from Post-Bloomfieldian linguistics and gradually replaced the latter.

The Chomskyan revolution can be seen as progress because it replaced the emphasis on procedures applied to the set of data by a productive interaction of hypotheses and tests in the empirical cycle.
\end{abstract}

In putting forward this thesis, ten Hacken does not mention the arguments which were advanced in favour of the opposite claim in a significant part of the historiographic literature we cited in Section 1, namely, that Syntactic Structures is an outgrowth of Post-Bloomfieldian linguistics rather than a radical revolutionary break with it (see Hymes \& Fought 1981, Murray 1994, Seuren 1998, Koerner 2002, and others).

\title{
2.3 The synchronic aspects of Chomskyan linguistics
}

Chapter 4 of ten Hacken's book is devoted to the synchronic relations between Chomskyan linguistics and further trends which the literature often considers as belonging to the generative movement (Sells 1985, Newmeyer 1998). Ten Hacken's precise analyses reveal both the common components and the differences between Chomskyan linguistics and the four theories already mentioned in Section 2.1 of the present review. Ten Hacken's starting point is Newmeyer (1998). Newmeyer differentiates between formalist and functionalist approaches. He assumes that within formalist approaches there are two trends: Chomsky's work and several other theories which differ from Chomsky's only in details of minor importance (Newmeyer 1998: 12). In contrast, ten Hacken shows that this picture painted by Newmeyer is inadequate. Instead, he argues that there are incommensurability effects in the discussions between the proponents of Chomskyan linguistics, on the one hand, and the leading personalities of these approaches, on the other - effects which bear witness to the presence of different research programs (p. 268). Nevertheless, although all four are rival research programs to Chomskyan linguistics, they do not diverge from the latter in the same way and to the same extent. LFG and Jackendoff's approach to language acquisition, language processing and the evolutionary origin of language have in common that they accept basic assumptions of Chomskyan

\footnotetext{
${ }^{3}$ As we will see in Section 3.1., Boeckx, in contrast, makes a sharp distinction between 'theory' and 'program' maintaining that the Minimalist Program is not a 'theory' but only an immature 'program'.
} 
linguistics in that they focus on competence and treat grammars as theories of competence. However, they assign different roles to language processing and learnability in the evaluation of grammars (p. 268). Chomskyan linguistics and Jackendoff's approach have in common that they accept that universal grammar describes the language faculty and that it explains the grammar of individual languages. They differ in their views on the emergence of human language in evolution and the criteria that Jackendoff (2002) applies in his argument for parallel architectures (p. 267).

The differences between Chomskyan linguistics, on the one hand, and GPSG and HPSG, on the other, are more fundamental, because the latter maintain a very different perspective on science. GPSG is formal science and HPSG neither accepts the mentalist conception of language nor commits itself to a non-mentalist view (p. 268). Showing that these four frameworks are different research programs and that they must not be simply subsumed under what Newmeyer (1998: 7) calls 'the generativist orientation', is an interesting achievement which sheds new light on the current trends in theoretical linguistics.

Chapter 5 starts with the claim that although Chomskyan linguistics has been accused of focusing only on grammar and neglecting other aspects of language, in recent years generative linguists have also shown a growing interest in fields beyond grammar (p. 273). Thus, ten Hacken discusses the relationship of Chomskyan linguistics to the following areas: first and second language acquisition, historical linguistics and language change, and linguistic communication (pragmatics). With respect to their impact on Chomskyan linguistics, he divides these areas into two categories: linguistic communication, which has a weak impact and the remaining fields which have a strong impact (p. 327). He emphasizes that, on the one hand, first and second language acquisition are closely connected with I-language, ${ }^{4}$ while linguistic change is seen as a side effect of the development of I-language. On the other hand, I-language is not immediately related to linguistic communication, so any approach to pragmatics which accepts the autonomy of competence seems to be compatible with Chomskyan linguistics.

\subsection{Ten Hacken's main findings and open problems}

2.4.1 Introductory remarks. In Section 1 of the present review article we asked three questions which we should now answer with respect to ten Hacken's book. In general, from the point of view of all three questions the evaluation of the book boils down to the conditional statement that if we accepted his background assumptions and the notions they involve, then Pius ten Hacken's work ought to be evaluated as an excellent analysis of the history and the impact of Chomskyan linguistics. It is clearly written and highly informative. The discussion of some basic tenets of the philosophy and history of science, the new definition of research program, and the analysis of both the diachronic and the synchronic relationship between Chomskyan linguistics and its alternatives lead to many new insights. The author's argumentative skill is remarkable; his reasoning is in many cases detailed, precise and coherent.

However, in spite of the obvious merits of the book, on closer inspection some of the background assumptions and the key arguments based on them appear to be problematic. Our main criticism will focus on a striking contradiction between the

\footnotetext{
4 'I-language' is an explication of the notion of 'competence' suggested in Chomsky (1986). I(nternalized)-language "is some element of the mind of the person who knows the language" (Chomsky 1986): 22). It is contrasted with E(xternalized)-language which was introduced as an explication of the earlier notion of performance.
} 
declared and the undeclared aim of the book. On the one hand it is explicitly stated that "[s]tarting the study of research programmes in linguistics with Chomskyan linguistics is not meant as a sign that I consider Chomskyan linguistics as representing the truth or as better than any other type of linguistics" (p. 39). On the other hand, ten Hacken's background assumptions point in the opposite direction, namely, the legitimization of Chomskyan linguistics. Let us see, how and why.

\subsubsection{On question 1: To what extent is the historiographic framework ten Hacken has} chosen tenable? The first question we asked concerns the tenability of the historiographic framework the author chooses. As already remarked, the concept of 'research program' is rooted in Kuhn's notion of 'paradigm' in that it retains the latter's intellectual, but dispenses with its social component. Ten Hacken considers the applicability of Kuhn's approach to linguistics as the precondition for the introduction of the new concepts and argues for the validity of Kuhn's approach.

Right at the outset, he addresses one of the main objections to the application of Kuhn's concept of 'paradigm' to linguistics. This well-known argument says that according to Kuhn (1970: 11-15), a paradigm is accepted by the whole discipline, whereas linguistics is pluralistic. But ten Hacken argues (p. 17) that Kuhn changed his view later and maintained the pluralism of paradigms both in the 'pre-paradigm' period and in the developed sciences:

As described by Hoyningen-Huene (1989: 143 f.), Kuhn first assumed that a paradigm must be adopted by all practitioners of a particular field. [...] Later, however, Kuhn changed his mind. In the postscript to the second edition, he assumes that in what he used to call a preparadigmatic situation all different schools have their own paradigm [1970: 178-179]. He also mentions "the relative scarcity of competing schools in the developed sciences" [Kuhn 1970: 209], which implies that two or more paradigms can coexist in the same field.

Ten Hacken accepts Hoyningen-Huene's interpretation, because he treats it as "the authorised exposition” of Kuhn's theory (p. 15). This is, at the outset, a clear case of "argument from authority", one of the classical fallacies. In the given context such a fallacy is all the more dangerous, because in the quotation it serves to legitimize two arguments which are otherwise anything but well-founded. As regards the first, the relevant passage in Kuhn's work ten Hacken refers to is as follows:

\footnotetext{
The nature of the transition to maturity deserves fuller discussion than it has received in this book, particularly from those concerned with the development of the contemporary social sciences. To that end it may help to point out that the transition need not (I now think should not) be associated with the first acquisition of a paradigm. The members of all scientific communities, including the schools of the 'pre-paradigm' period, share the sorts of elements which I have collectively labelled as 'a paradigm'. What changes with the transition to maturity is not the presence of a paradigm but rather its nature. Only after the change is normal puzzle-solving research possible. Many of the attributes of a developed science which I have above associated with the acquisition of a paradigm I would therefore now discuss as consequences of the acquisition of the sort of paradigm that identifies challenging puzzles, supplies clues to their solution, and guarantees that the truly clever practitioner will succeed. (Kuhn 1970: 178-179)
}

Here, Kuhn uses 'paradigm' - very confusingly — in different senses, but ten Hacken's argument ignores Kuhn's equivocation, relying on only one of Kuhn's claims, namely, that 'pre-paradigm disciplines have paradigms'. However, the next sentences in Kuhn's text maintain that the difference between the 'developed sciences' and the 'contemporary social sciences' remains, because the 'paradigms' of the former are not of the same nature as those of the latter. Thus, it does not follow 
that all disciplines should be treated equally with respect to the existence of paradigms and that, accordingly, linguistics has the same sort of paradigms as, for instance, physics.

Ten Hacken's second argument is problematic as well because he bases his claim on a sentence-fragment by Kuhn — and this is not a firm basis for drawing the conclusion he wants to draw.

Further arguments against the applicability of Kuhn's framework to linguistics were discussed in Oesterreicher (1977) and Percival (1976); so, ten Hacken tries to refute both these authors' doubts. According to Oesterreicher (1977), one of the reasons why Kuhn's notions are not applicable to linguistics is that linguistics is not a natural science. Ten Hacken's first counter-argument says the following (p. 30):

Chomsky on various occasions emphasises the biological basis of language. Chomsky [1976], for instance, refers approvingly to Lenneberg (1967) in this respect. Therefore, even if [Oesterreicher's (1977: 266-271) point that Kuhn's theory was crucially devised for natural sciences only] is valid, it is not obvious that it should apply to linguistics of the type pursued by Chomsky.

Nevertheless, from Chomsky's claim that his type of linguistics is a natural science it does not follow that his type of linguistics is indeed a natural science. Consequently, in this passage, too, the fallacy of 'argument from authority' has been committed. Ten Hacken's argument would be acceptable only if he could prove that this claim made by Chomsky is not mere rhetoric (e.g., in the sense of Murray 1994 or Harris 1993) or has not been motivated by Chomsky's efforts to legitimize the generative enterprise (e.g., in the sense of Lakoff 1989: 966 or Levine 2002: 326). However, as current debates on linguistic data in general (Sternefeld 2007) or on the Minimalist Program in particular (see, e.g., Lappin et al. 2000a, b, 2001, Seuren 2004) show, this is far from evident.

Ten Hacken's other counter-argument against Oesterreicher's claim that Kuhn's approach is inapplicable to linguistics “concerns Kuhn's reasons for distinguishing natural and social sciences" (p. 30; emphasis added: AK). In his interpretation Kuhn's main point is that education in the natural sciences, unlike in the social sciences, is entirely based on textbooks (pp. 30-31; cf. also Kuhn 1977 [1959]: 228). Ten Hacken quotes Matthews (1993: 98), according to whom this situation has changed with respect to linguistics because of the availability of widely used textbooks from the late 1960s. Ten Hacken concludes: "Therefore, the use of textbooks rather than original works in linguistics, at least in the past few decades, aligns it with the sciences for which Kuhn developed his theory” (p. 31). Ten Hacken's argument suggests that every field in which education is based on textbooks is a natural science. Obviously, the conclusion of the inference 'If in a field there are textbooks, then it is a natural science; in generative linguistics there are textbooks; therefore, generative linguistics is a natural science' is false, because its first premise is false. The reason why the premise is false is that it rests on what in logic is called a category error - and, with respect to the untenability of the argument, it does not matter whether it was committed by Kuhn or ten Hacken or both.

Turning to ten Hacken's treatment of Percival (1976), let us remind the reader that the discussion of the applicability of Kuhn's notion of 'paradigm' to linguistics “[...] appears to have subsided during the later 1970s, possibly as a result of Percival's (1976) paper which argued against the search for paradigms in linguistics [...]" (Koerner 1995: 8). Therefore, in order to change this situation, the arguments refuting Percival's tenets ought to be very powerful. Now, ten Hacken's main argument 
against Percival's claims is that the latter are based on the misrepresentation of Kuhn's ideas (pp. 33-34). The problem with this claim is of course that ten Hacken's interpretation of Kuhn's work is still only one of many possible interpretations and he cannot prove that his is the only correct one. Without being able to prove this, however, his counter-arguments lack the power they would require to refute Percival's stance.

In sum, the way ten Hacken takes sides for the applicability of Kuhn's notions to linguistics appears to aim at the legitimization of Chomskyan linguistics. The legitimizing argumentation can be reconstructed like this: (a) There are well-known differences between linguistics and the natural sciences to which Kuhn applied his notions of 'paradigm' and 'revolution'; (b) therefore, let us interpret Kuhn in such a way that his notions can be made apply to linguistics; (c) then we can claim that there have been paradigms and scientific revolutions in linguistics, and (d) we can also maintain that Chomskyan linguistics triggered a scientific revolution and the field is as prestigious as the natural sciences. ${ }^{5}$

\subsubsection{On question 2: How does the framework ten Hacken has chosen capture the} diachronic relationship between each stage of generative linguistics and its predecessors? Our answer to the second question raised in Section 1 will be similar to our answer to the first. If the author's background assumptions were acceptable, then he would show convincingly that the developmental stages of Chomskyan linguistics are different theories within the same research program and are not divided by revolutions, and conversely that the relationship between Post-Bloomfieldian structuralism and the early version of Chomskyan linguistics is indeed explained by the notion of 'revolution'.

The problematic nature of the author's background assumptions is closely connected to his detachment of the 'intellectual' from the 'social' with respect to the Kuhnian notions of 'incommensurability' and 'revolution'. As mentioned, ten Hacken defines 'revolution' as a change of research program. The main premise on which his argumentation rests is that the notion of 'incommensurability' provides the means for deciding whether one has to deal with two different research programs or merely different theories within the same research program. The difficulty with this argument is that Kuhn's notion of 'incommensurability' is basically social in nature, yet ten Hacken does not provide a new definition, nor does he clarify in what sense this new notion of 'incommensurability' dispenses with social aspects of science. ${ }^{6}$ On p. 15 the

\footnotetext{
${ }^{5}$ This striving for legitimization is of the same kind which, for example, Robin Lakoff pointed out when she wrote that

[...] the work of these scholars (especially Popper and Kuhn) has been taken up with passion within a number of the social sciences, where it has been treated as a litmus test for legitimacy or entry in the club. Therefore, the claims assume huge symbolic importance: If you can prove that the findings of your field are falsifiable, that your field has paradigms, etc., you are respectable. The implicit assumptions, of course, boggle the mind. (Lakoff 1989: 966; emphasis added: AK)

${ }^{6}$ Cf.: "Incommensurability makes it impossible to achieve a completely rational, decisive, judgement about the comparative value of [a theory] T1 and [a theory] T2 [...], but it does not exclude communication” (p. 17, emphasis added: AK). Now, however one defines communication, it involves the 'social'. Therefore, if 'communication' cannot be separated from the 'social' and 'incommensurability' cannot be separated from 'communication', then the notion of 'incommensurability’ must not dispense with ‘social’ aspects. In full accordance with this, in Chapter 3 "discussions between representatives of Post-Bloomfieldian and Chomskyan linguistics" are considered "in order to see whether such incommensurability effects can be detected" (p. 166; emphasis added: AK). But because such discussions are necessarily social in nature, this again conflicts
} 
author enumerates the four elements of disciplinary matrices and claims on p. 18 that these are intellectual properties of paradigms generating the problem of incommensurability. However, he does not clarify why and in what sense they can be called purely intellectual without possessing social aspects - for example, it is by no means automatically acceptable to say that values or exemplars are not socially influenced at all. Therefore, one wonders how ten Hacken can justify using the notion 'incommensurable' to distinguish between 'research programs' defined only in terms of the intellectual component of Kuhn's paradigms.

In a similar vein, excluding social factors from the notion of 'revolution' seems to be a kind of contradictio in adiecto, too.

A third and related difficulty is that, although ten Hacken's notions of 'research program' and 'incommensurable' require a clear distinction between the social and intellectual components of Kuhnian paradigms, he does not define the notions 'intellectual' and 'social' (the terms are not even included in the subject index). The author only tacitly presupposes the distinction between the social and intellectual aspects of science as if it were self-evident - but it is not, as we have learned from the Post-Kuhnian discussions in the philosophy of science and the sociology of knowledge.

In sum, ten Hacken makes great efforts to interpret Kuhn's terms in such a way that Chomskyan linguistics appears revolutionary and progressive. It is difficult to avoid the impression that - contrary to his claim which we quoted at the end of Section 2.4.1 - this conclusion was predetermined, rather than a result of historiographic analysis, and that the role of social factors in the 'success' of Chomskyan linguistics is being ignored, as though it came to dominate solely on its intellectual merits.

2.4.4 On question 3: How does the framework ten Hacken has chosen capture the synchronic relationships between Chomsky's generative linguistics and competing approaches within theoretical linguistics? As regards the third question, the complicated network of relations among Chomskyan linguistics, LFG, HPSG, GPSG and Jackendoff's approach, are described in a sophisticated and original manner. No doubt, ten Hacken's reasoning and the findings he arrives at are much more convincing than Newmeyer's (1998) claim. The following quotation illustrates this:

Nevertheless, it is interesting to see that a number of recurrent themes are elaborated in most or all of the four competing frameworks. Human language processing is more important in all of them than in Chomskyan linguistics. The incorporation of semantics was a driving force in GPSG. It led to what can be seen as a parallel architecture in HPSG and Jackendoff's linguistics. Also the use of features, structures and unification is shared by all four frameworks. Finally, the research programmes are not too far apart for ideas to be taken over from one into another. Typically, however, they are adapted to the receiving research programme and their further development is subject to evaluation criteria not shared by the original research programme. (ten Hacken, pp. 268-269)

This formulation is reminiscent of Nicholas Rescher's (1976: 118-119) tenet of 'retrospective re-validation' according to which during inquiry one reconsiders the same issues 'prismatically', i.e., from different, often incompatible, points of view. This process is cyclic and not circular, because "[...] one indeed returns to 'the same

with the author's intention to exclude social factors from his analysis. We see this yet again in Chapter 4, which focuses on the "incommensurability effects" between Chomskyan linguistics and its contemporary competitors. 
point' but does so at a different cognitive level” (Rescher 1976: 119; emphasis in the original). Even if ten Hacken does not explicate it, this prismatic nature of the network of linguistic theories is a very important insight that deserves further scrutiny.

In another respect, the way ten Hacken's concept of 'research program' is applied to the competitors of Chomskyan linguistics is not unproblematic. As already mentioned, he defines a revolution as a change in research program. In Chapter 4 it is argued that Chomskyan linguistics, LFG, HPSG, GPSG and Jackendoff's approach are different research programs which were triggered by perceived crises in Chomskyan linguistics. Therefore, it follows that these crises should have led to revolutions. However, ten Hacken does not draw this conclusion, and it is not clear why.

Furthermore, the author does not consider generative semantics among the competitors, although it was one of the most important rivals to Chomskyan linguistics which - due to the way it influenced Government \& Binding Theory and the Minimalist Program - still bears an intricate relation to the current state of Chomskyan linguistics. Therefore, it is an interesting and relevant question how ten Hacken's framework would treat this relationship. Nevertheless, we hypothesize that such an attempt would raise difficulties for his framework. Namely, as we know, a significant part of the literature maintains that the rise and fall of generative semantics was due to 'external', i.e., social and personal factors (Lakoff 1989, Harris 1993, Murray 1994, Huck \& Goldsmith 1995, Seuren 1996, 1998) - factors which the notion of 'research program' per definitionem excludes.

2.4.5 Concluding remarks concerning Ten Hacken's argumentation. To sum up, there is a tension between the generally ingenious and thought-provoking argumentation of the book - an argumentation which is intended to reveal the complicated relations between theories within the Chomskyan research program as well as those between different research programs — and the less convincing efforts to prove the applicability of Kuhn's categories to generative linguistics. Contrary to what the author tacitly assumes, proving this is not a necessary condition for the introduction and application of the new notion of 'research program'. This notion is sufficiently different from Kuhn's conception to be an autonomous framework, because social aspects of science that are substantially important to the latter have been excluded from the former. Therefore, the claim 'Kuhn's theory is applicable to linguistics' is not needed for concluding that 'Chomskyan linguistics is a research program'. A Kuhnian starting point is presented as a well-founded basis for reasoned conclusions, but it serves only to legitimize the generative enterprise. Getting rid of the Kuhnian background and developing an autonomous approach to the diachronic and synchronic relations between Chomskyan linguistics and its competitors may be a fruitful continuation of the author's work.

\section{Minimalism as a Lakatosian scientific research program}

\subsection{The notion of 'research program'}

Boeckx's book can be characterized according to the same criteria as ten Hacken's, but with different results. First, unlike ten Hacken, Boeckx introduces the reader to one particular version of generative grammar, namely, the Minimalist Program. Therefore, the point of reference for both the diachronic and the synchronic considerations is minimalism. Second, Boeckx, similarly to ten Hacken, bases his approach on central tenets of the philosophy of science, but chooses a different 
framework: he opts for Imre Lakatos's (1970) notion of 'scientific research program'. What makes Boeckx's work different from other introductions to minimalism is that instead of discussing technical details, it focuses on minimalism's methodological foundations with a broad philosophical and interdisciplinary perspective.

The first chapter gives a bird's eye view of the central ideas of the Minimalist Program. So, at the outset, the reader is introduced to the main issues which will be dealt with later in an easily understandable manner. Already at this point Boeckx places minimalism within the overall framework of the Principles \& Parameters approach, touches on its main tenets and emphasizes its advantages. He highlights the following features of minimalism: (a) the leading principles of grammar are economy, virtual conceptual necessity, perfection and symmetry; (b) the analytic and explanatory apparatus has been radically simplified; (c) grammar has been provided with a firm biological foundation; (d) the Galilean style in science has been applied; (e) as minimalism is not a well-established theory, but only a program, it enables us to evaluate alternative solutions to various problems over a wider range than a mature theory would tolerate.

It is this latter tenet that is at the heart of the book and which motivates the author's line of argumentation (p. 5). Namely, contrasting the notion of 'program' with that of 'theory' highlights the fact that (p. 6; emphasis added: AK)

[...] we are still far from having a fully-fledged minimalist theory of language. This fact has important repercussions for what it means to do research in the minimalist program. A program is open-ended, it may take a long time to mature, it allows researchers to make maximal use of their creativity as they try to move from minimalist guidelines to concrete principles, it makes room for multiple, not necessarily mutually consistent and compatible perspectives, and it cannot be evaluated in terms of true or false, but in terms of fecund or sterile.

This quotation expresses very well those aspects which a suitable methodological framework of minimalism is expected to capture. In Boeckx's view the only such framework is Lakatos's notion of 'scientific research program', which he therefore adopts (pp. 6-7, 87-91). A scientific research program in Lakatos's sense comprises a core that corresponds to the essence of the program in that it includes those components which are protected from refutation. The core is supplemented by auxiliary hypotheses which might change flexibly or which may yield alternatives that are different from each other yet all compatible with the core. Accordingly, the main task of characterizing minimalism is the identification of the core and the alternative auxiliary hypotheses. Before turning to this task, the author reveals the historical roots of the Minimalist Program.

\subsection{The diachronic aspects of minimalism}

It is Chapter 2 that is devoted to the historiographic overview. Unlike ten Hacken, Boeckx does not aim to draw a comprehensive picture of the development of linguistics from Post-Bloomfieldianism through several stages of development to Minimalism, nor does he present a precise reconstruction of the turning points. Rather, he views and evaluates the past solely from the perspective of minimalism: "My only goal in retracing the roads previously taken is to locate minimalism within the larger map of linguistics" (p. 12; emphasis added: AK).

Although Boeckx does not call the revolutionary impact of Chomsky (1957) into question, in his opinion the key work that triggered the rise of generativism simultaneously with the abandonment of Post-Bloomfieldian structuralism was 
Chomsky's (1959) famous review of Skinner (1957), because it initiated the development of biolinguistics (p. 16).

Clearly, if the starting point of generative linguistics is interpreted in this way, then its further intellectual history can be seen as a linear process leading to the current interplay between biology and minimalism. This is the perspective from which Boeckx identifies the major driving forces of the development that culminated in the Minimalist Program. The first of these is that a theory of language should aim at explanatory adequacy, which is reached if the theory accounts for the biologically given structure which makes it possible for children to select a descriptively adequate grammar on the basis of primary linguistic data (pp. 18-19; Chomsky 1965: 25). Yet this aim brings with it - as the next driving force of the development of generative linguistics - the logical problem of language acquisition. In order to explain its solution, Boeckx highlights the necessity of assuming the biological basis of language acquisition, regarded as the 'language organ' which constrains the range of possible grammars (p. 27). Against the background of this hypothesis, the next issue is how the language organ can be accounted for in computational terms. As an answer, Boeckx provides a concise overview of Chomsky's early argument against modeling grammar by finite state machines and sketches the process that led — via phrase structure grammars, transformations and conditions on transformations - to the Principles \& Parameters approach. This historical process provides, according to Boeckx, the two major pillars on which the Minimalist Program rests (p. 60): first, the solution of the logical problem of language acquisition within the Principles \& Parameters approach, presupposing the language organ in a biological sense, and second, the emphasis on the formal tools of the theory of language which conform to the Galilean style in science. The latter assumes that nature is governed by laws that can be understood in terms of mathematical structures.

\subsection{The synchronic aspects of minimalism}

The synchronic aspects of the Minimalist Program are discussed in Chapters 3 through 6. They include the following main topics: the identification of the core of the program; in connection with this, the consideration of auxiliary hypotheses that go beyond the core and open up alternatives often not compatible with each other but compatible with the core; and the impact of minimalism on linguistics and biology.

As regards the first of these, the core of the program - in Lakatos's sense includes a tripod which rests on the Principles \& Parameters approach: virtual conceptual necessity, economy and symmetry.

With respect to the second topic - the auxiliary hypotheses that supplement the core - the basic insight is that (p. 94; emphasis added: AK)

[a]s for auxiliary hypotheses, their existence simply indicates that there are various ways of articulating and defending a given research program. [...] Programs allow researchers to try different combinations of the basic tenets, and to develop them with different emphases, vantage points, and ways of directing attention. The core will remain as a nucleus for observations and reflections, but beyond that there is great freedom and flexibility.

Along these lines, several examples are discussed which show how within minimalism alternative solutions to problems have been suggested (95-109 and Chapter 5) and what the limits are beyond which alternatives must not transgress (104-105) because to go farther would be incompatible with the core. Boeckx's overview thus makes it possible to understand the relationship between the core and its alternative realizations in minimalism. 
The third topic exemplifies the significance of minimalism by elucidating two issues: how minimalism goes beyond explanatory adequacy and how it can resolve the tension between the search for general laws, simplicity and perfectness on the one hand, and the seemingly very different methods applied in biological inquiry on the other. It is the previously emphasized Galilean style in science that is at the heart of both issues. The deepest question of the natural sciences is: why is nature the way it is? The Galilean answer says that nature is the way it is "[...] because that is the simplest way it could be” (p. 115); in this sense, nature is 'perfect'. Minimalism goes beyond explanatory adequacy insofar as it asks the question resulting from this Galilean worldview: to what degree is language perfect? (p. 116). Nevertheless, the problem emerges that while the Galilean style in science is rooted in physics, minimalism considers itself to be biology, and biology appears to be very different from physics. Biology has not been able to adopt the Galilean style because primarily due to the diversity of the phenomena it investigates - its aim is not to reveal the kind of natural laws which are the subject matter of physics (131-138). Therefore, minimalism challenges biology. Boeckx argues that this challenge can be met because "[...] the adherence to the Galilean style [...] promises to yield important hypotheses not just in the strictly linguistic realm of grammatical analyses but also in the realm of biology at large" (p. 151).

Although the main emphasis is on the methodological, foundational and conceptual status of minimalism, the author also illustrates these issues with numerous examples from the practice of minimalist analyses. He devotes much space (159-190) to showing how general minimalist principles are put to use when problems of control, sluicing, parasitic gaps, existential constructions and the like are at stake. The discussion of the way minimalism treats these phenomena is non-technical, instructive and easy to follow.

\subsection{Boeckx's main findings and open problems}

3.4.1 Introductory remarks. Boeckx's work is a very good overview of the basic ideas underlying minimalism. It is a great advantage of the book that it dispenses with the technical apparatus of linguistic analyses and concentrates on the guiding ideas of the program. Moreover, the fact that the author embeds these ideas into the broad context of the methodology of the natural sciences helps the reader understand the epistemological context of present-day science in a way that remains hidden in most linguistics textbooks. Nevertheless, despite these merits, Boeckx's work raises problems analogous to those of ten Hacken's book. Let us see now how the three questions we asked in Section 1 of this article can be answered.

3.4.2 On question 1: To what extent is the historiographic framework Boeckx has chosen tenable? As regards the first, while ten Hacken's quite different notion of 'research program' is applicable to the whole history of generative linguistics, Boeckx restricts the Lakatosian framework to the Minimalist Program only (see, e.g., pp. 7, 84-109). In principle the choice of this framework may be reasonable because - with few exceptions such as Huck \& Goldsmith (1995) and Schmitter (1998) — it has not been applied to linguistics although it is one of the most renowned approaches to the philosophy and history of science. Nevertheless, there is some discrepancy between the aim of the book as explicitly stated and the way the author in fact makes use of Lakatos's approach. On the one hand, Boeckx explicitly states at several places that he does not want to defend minimalism and does not consider his historical overview as Whig history. Here are some examples: 
I do not intend this book to be a defense of the minimalist program against the critiques that have been leveled at it over the years. (p. 11)

My goal is to lay bare the logic of the program and let it speak for itself. (p. 12)

I am aware that very often scientists who take an interest in their subject's past often indulge in what Butterfield (1931) called 'the Whig interpretation of history' [...]. The historical reconstruction I attempt here does not just emphasize past successes; it also points out limitations of previous research [...]. I cannot glorify minimalism [...]. (p. 13)

On the other hand, the reader may get the impression that in spite of these declarations Boeckx's primary goal is to legitimize the uncertainty, the incoherence, and the contradictory and empirically unfounded nature of minimalism, all of which have been targets for critics of the Program. For instance:

For me, minimalism is worth pursuing because, to the extent that one can reach explanations by following minimalist guidelines, such explanations will have a deep and pleasing character. (p. 13)

Programs take time to mature, and rigor cannot be required in the beginning. (p. 91)

[...] I want to encourage the pursuit of the minimalist program even if some of its ideas are taking a long time to mature. (p. 93)

Because it is my overall goal in this book to show that the minimalist program has great merits, I want to show that the criticism is in fact unwarranted, and that the pursuit of the minimalist program in syntactic theory is not only legitimate [...] but also rewarding. (p. 154)

The tool for legitimacy is Lakatos's concept of 'scientific research program'. Boeckx's (84-109) legitimizing argumentation strategy can be reconstructed as follows: (a) Minimalism is not a well-established, rigorous theory based on a solid formal and empirical foundation, but only an immature program. (b) Lakatos's historiographic framework describes even the most significant achievements of the natural sciences with the notion of 'research program' (p. 88), which can also be applied to minimalism. (c) As a result, in spite of its immaturity and the lack of rigor, minimalism can also yield highly significant scientific findings.

Boeckx seems to confront the notion of 'theory' with that of 'program', suggesting that Lakatos was defending the latter's immaturity, uncertainty and inconsistency against the former's maturity and rigor. However, Lakatos did not aim at the legitimization of programs in this sense. Lakatos pursued a very different aim: his notion of 'scientific research program' served to reconcile Popper's and Kuhn's ideas and thence to solve certain basic problems in the history and philosophy of science.

3.4.3 On question 2: How does the framework Boeckx has chosen capture the diachronic relationship between each stage of generative linguistics and its predecessors? As regards the second question raised in Section 1 of the present article, the book both leads to important insights and leaves important problems open, although not infrequently in a hidden rather than explicit way. Let us turn to the open problems first.

Since Boeckx confines the application of the Lakatosian framework to minimalism, it is not clear how, against this framework, earlier stages should be characterized. Namely, the motivation for adapting Lakatos's notion is that minimalism is 'only' a program — immature and far from being rigorous. One option for the interpretation of earlier stages would be not to characterize them as programs in this sense. Then it would follow that they should be seen as more mature and more rigorous theories. But then the question arises why such mature theories were 
replaced by an immature program. Another possibility would be to assume that, on the contrary, earlier stages also fit the Lakatosian framework. Then, however, distinguishing the former from minimalism by highlighting the latter's programmatic nature seems to be unmotivated.

Moreover, as we know, 'revolution' is a key concept of the historiography of generative linguistics. Boeckx mentions it at several places in the book but does not regard it as central. Nevertheless, the way it appears in the book is obscure. In particular, he lays great emphasis on the claim that the Minimalist Program is rooted in the Principles \& Parameters approach:

If, as I have argued, P\&P provides the context of emergence for minimalism, the specific and best-worked-out version of the P\&P approach known as Government-Binding theory (GB) provides specific (technical) principles ('details') from which minimalist guidelines - what I will define as the conceptual core of minimalism - could be extracted. (61-62)

From this it follows that there is continuity between Minimalism and Government \& Binding theory. However, 'scientific revolution' is defined as follows:

[...] Lakatos assumes that scientific revolutions come about once scientists join a progressive program at the expense of a degenerating competing one. But Lakatos notes that, while it is a matter of intellectual honesty to keep the record public, it is not dishonest or irrational to stick to a degenerating program and try to turn it into a progressive one. (p. 91)

This quotation gains relevance insofar as the author remarks in a footnote on p. 89 that GB was 'degenerating' in Lakatos's sense. If this is so, then either minimalism is a revolution according to the first sentence of the last quotation; or GB, as a degenerating program, was turned into a progressive one, i.e., minimalism. The fact that Boeckx does not take sides explicitly is all the more problematic because he very often affirmingly quotes the views of Piatelli-Palmarini who, as is well-known, called the Minimalist Program a "revolution within a revolution" (Piatelli-Palmarini 1998: xxii), and who characterizes minimalism as follows:

[...] this brand of linguistics is well on its way to becoming a full-blown natural science, offering a serious promise of an advanced field of scientific inquiry whose idealizations, abstractions, and deductions will eventually match in depth and subtlety those of the most advanced domains of modern science. Generative grammar is turning into a natural science already, because of what it is now, not because of what it might one day turn into, when neural imaging and neurobiology will have provided dramatic new refinements. (PiatelliPalmarini 1998: xxv; emphasis added: AK)

This is of particular interest in this context because, although Piatelli-Palmarini concurs with Boeckx in promoting minimalism, he claims here that minimalism is an advanced and mature natural science - the opposite of Boeckx's main argument. One really wonders which of the two claims is correct: is minimalism, as PiatelliPalmarini maintains, "well on its way to becoming a full-blown natural science [...] because of what it is now" (Piatelli-Palmarini 1998: xxv); or is Boeckx right when he says that "we are still far from having a fully-fledged minimalist theory of language" (p. 6)? The undecidability of this question bears witness to the fact that the main aim of both arguments is the legitimization of the Minimalist Program, and that end justifies completely opposite means, claiming that minimalism is a mature science or claiming that it is an immature research program.

Turning to the insights Boeckx's book yields with respect to our second question, he also reveals a very important aspect of the relationship between minimalism and 
earlier stages of generative linguistics. In particular, as regards the return of minimalism to certain findings of generative semantics, he remarks that "[a]s is perfectly natural in the case of conceptual shift, novel approaches lead to the revival of earlier analyses. Once put in a different theoretical setting, such analyses enjoy a new lease of plausibility" (p. 178; emphasis added: AK). In the corresponding footnote he adds: "[...] there is nothing odd, irrational or inconsistent about recruiting old tools for new purposes in a different theoretical context" (p. 179; emphasis added: AK). That is, a later stage of development such as minimalism may feed back to earlier findings and reconsider them. However, one does not thereby return to the same starting point, but to a stage of scientific knowledge which is seen through the prism of the new framework. For example, “[...] lexical decomposition in the current theory takes place within a different conceptual and theoretical setting, and does not signify a return to the model of grammar explored within generative semantics [...]" (p. 178n.14). This insight of Boeckx is much more important than even he supposes because it reveals an aspect of generative linguistic research which has significantly shaped its development but which has not been acknowledged adequately so far. The process thus touched on appears to be a cyclic process of inquiry that reminds the present reviewer of Nelson Goodman's (1983 [1955]) idea later referred to by others as 'reflective equilibrium' or Rescher's (1976) similar notion of 'retrospective revalidation'. It is not evident, however, how the mechanism we quoted can be integrated into the Lakatosian framework - this is all the more problematic because, as already mentioned, it is not clear whether Boeckx restricts the scope of this framework to minimalism or wants to extend it to the whole history of generative linguistics.

3.4.4 On question (3): How does the framework Boeckx has chosen capture the synchronic relationships between Chomsky's generative linguistics and other disciplines such as physics and biology; and between different versions of minimalism? In answering the third question we asked in Section 1, we find that the book highlights a series of important issues. Unlike ten Hacken, Boeckx does not go into the relationship between Chomsky's approach and its competitors such as LFG or GPSG. Rather, he discusses the relationship between the core and its different manifestations in specific solutions to the particular problems. That minimalism is flexible enough to allow different alternative realizations of the minimalist core is important in at least two respects. First, because throughout the decades leading up to the emergence of minimalism, the Chomskyan version of generative grammar was anything but tolerant. The fact that within minimalism today there is toleration of alternative lines of argumentation and that pluralism within the limits of the core is acknowledged is an important change of methodological attitude. Second, there is no doubt that our knowledge of language will be enriched if it is viewed simultaneously from different perspectives. The Minimalist Program "[...] allows every researcher to [...] consider and reconsider the entire architecture of the language faculty by simply starting from different corners of the map" (p. 95). This state of affairs within minimalism seems to be analogous to that kind of prismatic, retrospective re-validation of hypotheses which we mentioned. That Boeckx has tacitly realized that minimalism permits the existence of these prismatic relations between alternatives is of great significance, even if he does not explicate them.

However, with respect to the synchronic relation between minimalism and disciplines like physics and biology, the author's reasoning is not unproblematic. Here 
again there is a very obvious conflict between what Boeckx says and what he does. He explicitly states (pp. 110-111):

Let me stress right from the start that, although I will very often make reference to theoretical physics in the pages that follow, it is not (contra Levine 2002: 326) "to exploit the prestige of the natural sciences” (what is sometimes called 'physics-envy').

Contrary to this claim, he makes ample use of arguments from authority. There are an unusually large number of quotations in the book, many of which are from physicists and biologists. These quotations are used as premises in analogical inferences the conclusion of which is that research in minimalism is as scientific as research in these disciplines. Furthermore, the author makes great efforts to resolve the contradiction between biology and the methodology of Galilean style science in order to be able to call minimalism 'biology' without having to give up the desideratum of pursuing Galilean-style science (p. 123-151).

3.4.5 Concluding remarks concerning Boeckx's argumentation. In sum, Boeckx's book is certainly a valuable piece of work. It introduces the reader to the central ideas of minimalism in an understandable and non-technical way. Besides its usability as a textbook, it reveals interesting findings which mainly affect the internal relationship between the core and the auxiliary hypotheses within the program as well as the program's assumed place within the system of scientific disciplines. Nevertheless, as we have seen, in other respects the application of the framework chosen is not sufficiently consequential.

\section{Summing up}

The differences between the two notions of 'research program' are significant. Whereas ten Hacken considers his notion as the genus proximum to 'theory', Boeckx contrasts 'program' with 'theory'. For ten Hacken the Minimalist Program is a 'theory' within the research program of Chomskyan linguistics. For Boeckx it is not a theory but an immature program. However, in spite of the differences of the two notions of 'research program', both the merits and the shortcomings of the two books seem to be analogous. We begin with summarizing their common merits.

First of all, the works under review are without doubt impressive intellectual achievements. Second, the importance of both books lies in the fact that they address fundamental problems both of the historiography of generative linguistics and its conceptual basis which they try to solve with the help of the given framework. Their primary impact is that they enrich the range of possible historiographic accounts of generative linguistics and through this they pave the way for new directions in later research. Third, they yield insights that seem to go beyond what has been discussed in the literature we mentioned in Section 1 and raise novel problems to be solved in the future. For example: What is the nature of the 'retrospective re-validation' of findings during the history of generative linguistics? How can the 'prismatic' nature of the relations between Chomskyan linguistics and its rivals such as LFG, HPSG etc. be reconstructed? How can the 'prismatic' interplay between alternatives within minimalism be precisely reconstructed? How can the argumentation structure of generative linguistic theories be captured? How can the cyclic nature of the development of generative grammar be accounted for?

The first generalization from our criticism in Sections 2.4 and 3.4 is that the authors have an undeclared aim of legitimizing Chomsky's linguistics. In this respect the two books are not significantly different from many other propagandistic 
publications such as, for example, those by Newmeyer (see, e.g., Murray 1981, 1989, Tomalin 2008: 11, Lakoff 1989: 940; Koerner 2002: 157-196 passim). Second, so as to achieve this aim, they make ample use of dubious argumentative means such as argument from authority, false premise, category error, contradictio in adiecto and inconsistent reasoning. Third, both works simply ignore the state of the art as if the literature surveyed in Section 1 did not exist. This strategy of ignorance results in circularity at two levels. On the one hand, the two contrasting notions of 'research program' have been introduced in order to justify certain theses with respect to Chomskyan linguistics. Therefore, the frameworks will indeed justify them, and make Chomskyan linguistics appear exactly as the authors would like it to appear. On the other hand, circularity serves the self-legitimization of the frameworks themselves: because they seem successful in justifying the theses for the justification of which they have been introduced, they are seen as adequate means of accounting for relevant properties of Chomsky's linguistics.

Consequently, in order to arrive at a better understanding of the place which generative linguistics assumes today within the broad context of linguistics and the role it has played during the past five decades, the merits and the shortcomings of both notions of 'research program' should be carefully analyzed. The main question, then, is, whether, and if so, how, their merits can be retained without commitments to the questionable way in which they have been applied. Neither of them is satisfactory, and the search for an appropriate historiographic framework for generative linguistics must continue. The shortcomings of the two books seem to result primarily from the legitimizing the application of prefabricated frameworks: in ten Hacken's case that of Kuhn (1970) and in Boeckx's case that of Lakatos (1970). Conversely, the merits of both works are seen most strikingly at points where the authors' argumentation can be detached from the latter and the authors follow their own line of reasoning.

In sum, our criticism reflects the idea that the main guiding principle for the historiography of generative linguistics should be what Koerner expressed as follows:

\begin{abstract}
It is important to realize [...] that the historians of linguistics because of the particular nature of the subject of investigation, namely theories of language (as well as theories of linguistics) and their evolution through time, must find their own framework, methodology and epistemology, and cannot expect to be able to apply methods and insights from other fields directly to their own subject of investigation [...] (Koerner 1995: 7-8, emphasis added: AK)
\end{abstract}

We still have a long way to go to achieve this desideratum in the historiography of generative linguistics.

\title{
REFERENCES
}

Bloor, David. 1976. Knowledge and Social Imagery. London: Routledge.

Butterfield, Herbert. 1931. The Whig Interpretation of History. London: Bell.

Chomsky, Noam. 1957. Syntactic Structures. The Hague: Mouton.

Chomsky, Noam. 1959. Review of Skinner (1957). Language 35.26-58.

Chomsky, Noam. 1965. Aspects of the Theory of Syntax. The Hague: Mouton.

Chomsky, Noam. 1976. "On the Biological Basis of Language Capacities". The Neuropsychology of Language: Essays in honor of Eric Lenneberg ed. by Robert W. Rieber, 1-24. New York: Plenum. (Repr. in Chomsky, Rules and Representations, 185-216. New York: Columbia University Press, 1980.)

Chomsky, Noam. 1986. Knowledge of Language: Its Nature, Origin, and Use. New York \& Westport, Conn.: Prager.

Chomsky, Noam. 1995. The Minimalist Program. Cambridge, Mass.: MIT Press. 
Chomsky, Noam. 2002. On Nature and Language. Cambridge: Cambridge University Press.

Chomsky, Noam \& Morris Halle. 1968. The Sound Pattern of English. New York: Harper \& Row.

Goodman, Nelson. 1983 [1955]. Fact, Fiction, and Forecast. Cambridge, Mass.: Harvard University Press.

Grewendorf, Günther. 1995. "Interview mit Noam Chomsky: Über Linguistik und Politik”. Sprache als Organ - Sprache als Lebensform by Grewendorf, 219-236. Frankfurt am Main: Suhrkamp.

Harris, Randy Allen. 1993. The Linguistics Wars. New York \& Oxford: Oxford University Press.

Hoyningen-Huene, Paul. 1989. Die Wissenschaftsphilosophie Thomas S. Kuhns. Braunschweig: F. Vieweg.

Huck, Geoffrey J. \& John A. Goldsmith. 1995. Ideology and Linguistic Theory: Noam Chomsky and the Deep Structure Debates. London \& New York: Routledge.

Hymes, Dell \& John Fought. 1981. American Structuralism. The Hague: Mouton.

Jackendoff, Ray. 2002. Foundations of Language: Brain, Meaning, Grammar, Evolution. Oxford: Oxford University Press.

Jäger, Ludwig. 1993. “'Language, what ever that may be': Die Geschichte der Sprachwissenschaft als Erosionsgeschichte ihres Gegenstandes”. Zeitschrift für Sprachwissenschaft 12.77-106.

Joseph, John E. 1995. “The Structure of Linguistic Revolutions”. Historiographia Linguistica 22.379-399.

Koerner, E.F.K. 1995. "Historiography of Linguistics". Concise History of the Language Sciences: From the Sumerians to the Cognitivists ed. by E.F.K. Koerner \& R. E. Asher, 7-16. Oxford \& New York: Pergamon.

Koerner, E.F.K. 2002. “The 'Chomskyan Revolution' and Its Historiography”. Toward a History of American Linguistics, 151-209. London \& New York: Routledge.

Kuhn, Thomas S. 1970 [1962]. The Structure of Scientific Revolutions. 2nd ed. Chicago: University of Chicago Press.

Kuhn, Thomas S. 1977 [1959]. “The Essential Tension”. The Essential Tension: Selected studies in scientific tradition and change by Thomas S. Kuhn, 225-239. Chicago: University of Chicago Press.

Lakatos, Imre. 1970. "Falsification and the Methodology of Scientific Research Programmes". Criticism and the Growth of Knowledge ed. by Imre Lakatos \& Alan Musgrave, 91-195. Cambridge: Cambridge University Press.

Lakoff, Robin. 1989. "The Way We Were; or; the real truth about Generative Semantics. A memoir”. Journal of Pragmatics 13.939-988.

Lappin, Shalom, Robert D. Levine \& David D. Johnson. 2000a. "The Structure of Unscientific Revolutions”. Natural Language and Linguistic Theory 18.665-671.

Lappin, Shalom, Robert D. Levine \& David D. Johnson. 2000b. "The Revolution Confused: A response to our critics". Natural Language and Linguistic Theory 18.873-890.

Lappin, Shalom, Robert D. Levine \& David D. Johnson. 2001. “The Revolution Maximally Confused”. Natural Language and Linguistic Theory 19.901-919.

Laudan, Larry. 1977. Progress and Its Problems. Berkeley \& Los Angeles: University of California Press.

Lenneberg, Eric H. 1967. Biological Foundations of Language. New York: John Wiley \& Sons. 
Levine, Robert D. 2002. Review of Uriagereka (1998). Language 78.325-330.

McCawley, James D. 1976. "Introduction”. Notes from the Linguistic Underground ed. by James D. McCawley, 1-19. New York: Academic Press.

Matthews, Peter H. 1993. Grammatical Theory in the United Staes from Bloomfield to Chomsky. Cambridge: Cambridge University Press.

Murray, Stephen O. 1981. Review of Newmeyer (1980). Historiographia Linguistica 7.107-112.

Murray, Stephen O. 1989. "Recent Studies of American Linguistics”. Historiographia Linguistica 16.14-71.

Murray, Stephen O. 1994. Theory Groups and the Study of Language in North America: A social history. Amsterdam \& Philadelphia: John Benjamins.

Newmeyer, Frederick J. 1986. "Has There Been a 'Chomskyan Revolution' in Linguistics?”. Language 62.1-18.

Newmeyer, Frederick J. 1998. Language Form and Language Function. Cambridge, Mass.: MIT Press.

Oesterreicher, Wulf. 1977. "Paradigma und Paradigmenwechsel: Thomas S. Kuhn und die Linguistik”. Osnabrücker Beiträge zur Sprachtheorie 3.241-284.

Percival, W. Keith. 1976. “The Applicability of Kuhn's Paradigms to the History of Linguistics”. Language 52.285-294.

Piatelli-Palmarini, Massimo. 1998. “Foreword”. Uriagereka 1998.xxi-xxxvi.

Rescher, Nicholas. 1976. Plausible Reasoning. Assen \& Amsterdam: Van Gorcum.

Schmitter, Peter. 1998. "Der Begriff des Forschungsprogramms als metahistoriographische Kategorie der Wissenschaftsgeschichtsschreibung der Linguistik". Metahistoriography: Theoretical and methodological aspects of the historiography of linguistics ed. by Peter Schmitter \& Marijke van der Wal, 133-152. Münster: Nodus.

Searle, John. 1972. “Chomsky's Revolution in Linguistics”. The New York Review of Books 19.16-24.

Sells, Peter. 1985. Lectures on Contemporary Syntactic Theories: An introduction to Government-Binding Theory, Generalized Phrase Structure Grammar, and LexicalFunctional Grammar. Stanford: CSLI.

Seuren, Pieter A. M. 1996. Semantic Syntax. Oxford: Blackwell.

Seuren, Pieter A. M. 1998. Western Linguistics: An historical introduction. Oxford: Blackwell.

Seuren, Pieter A. M. 2004. Chomsky’s Minimalism. Oxford: Oxford University Press.

Skinner, B. F. 1957. Verbal Behavior. Englewood Cliffs, N.J.: Prentice Hall.

Sternefeld, Wolfgang, ed. 2007. Data in Generative Grammar. (= Theoretical Linguistics 33: 3). Berlin: Mouton de Gruyter.

Thorne, James Peter. 1965. Review of Paul M. Postal, Constituent Structure: A study of contemporary models of syntactic description (Bloomington: Indiana University; The Hague: Mouton, 1964). Journal of Linguistics 1.73-76.

Tomalin, Marcus. 2008 [2006]. Linguistics and the Formal Sciences: The origins of Generative Grammar. Paperback ed. Cambridge: Cambridge University Press.

Uriagereka, Juan. 1998. Rhyme and Reason: An introduction to minimalist syntax. Cambridge, Mass.: MIT Press.

Woolgar, Steve 1988. Science: The very idea. Chichester: Harwood; London: Tavistock.

Author's address:

András Kertész

Department of German Linguistics 
University of Debrecen

P. O. Box 47

H-4010 DEBRECEN

$\mathrm{H}$ u n g a r y

e-mail: andras.kertesz@t-online.hu 